\title{
Idol Commercialization in China
}

\author{
Lucy Wang $^{1}$ \\ ${ }^{1}$ Concord Academy MA 01742, jiadian.wang@ concordacademy.org
}

\begin{abstract}
Produce 101 has been successful as a hot and new fandom industry-based show since 2018 in China under the influence of social media and video platforms. Based on the result of the case study example, this article studies how Produce 101 helps some trainees gain huge attention through marketing, and promote large-scale fund-raising activities through specific voting channels. In addition, the paper analyzed how sponsors generate revenue by selecting some contestants as their product endorsers. As a result, the popularity of the trainees turned into a marketing strategy that allows the endorsers gaining huge profits.
\end{abstract}

Keywords: Youth With You, Crowdfunding, Celebrity Endorsement, Popularity index.

\section{INTRODUCTION}

As Produce 101 successfully gained huge popularity in Korea, Aiqiyi (one of the major video apps) released the same type of show named Youth With You in China in 2019. It is a reality show focusing on idol production, which selects nine trainees to debut as a boys' group from a hundred and nineteen in total through four months of closed training and stage performances. Audiences vote through Aiqiyi and a code in the selected beverage on a card, the trainee who gets most of the votes will debut as the center in the group. Undoubtedly, the show also gained huge attention compared to other Chinese reality shows. The audiences have a stronger participation in the show because their votes can decide whether the trainee they pick can successfully debut in the group. As a result, the trainees need to show their personalities and hard-core performing skills to become outstanding out of hundreds of contestants on the same show Other than the focus on the trainees themselves, the fans also gather together to maximize the votes through a large crowdfunding practice. In addition, the sponsors also select some of the trainees for celebrity endorsement, which is a marketing strategy that a brand selects one or some celebrities to advertise a specific product or service. As a result, this article will analyze why certain trainees can gain popularity, crowdfunding, and fandom economy, and celebrity endorsement under the influence of media in Youth With You Season Three through a case study example of Tony $\mathrm{Yu}$, a contestant in the show.

\section{LITERATURE REVIEW}

Celebrity culture became a pervasive preoccupation among the famous people majoring in the entertainment and sports industry, their visibility and social influence became extensive after the prevalence of social media. Taking the advantage of celebrity visibility among customers, many industries started to invite celebrities as the endorsers of their brands [1].

To become competitive in the current marketing environment, the companies use celebrity endorsement as an important approach to strategic positioning in marketing and advertising. As the companies take advantage of the celebrities 'public recognition and social influence, they put themselves at risk of becoming vulnerable or less profitable if certain celebrities are perceived in a negative light or not seen as credible spokespeople by the public. Khatri [2] suggested that celebrity endorsement mainly focuses on highproduction cost margin products that involve a largely diverse customer base. The fast-moving consumer goods engaged in monopolistic competition are usually the targeted products for celebrity endorsement because of their utility and price. Besides, it is important to determine how celebrity endorsement affects customer purchase decisions. A few hypotheses were being discussed, "celebrities have credibility on expertise that makes the product more desirable or enhances perceptions of quality (iii) the celebrity endorser's image is transferred to the product so that those who use the product are associated with the image. Experiments suggest that in certain situations, celebrity endorsement can enhance recall and consumer assessment of the products" [3]. 
Furthermore, the success of celebrity endorsement also depends on social media platforms. Currently, social media takes up a large part of people's daily lives. As a result, the social media platforms create a stronger bond between the celebrities and the consumers that promotes celebrity endorsements since the celebrities can update and interact with the consumers frequently [4]. During the process of interactive communication through social media, the consumers can experience intensified intimacy which increases the credibility of the products endorsed by the celebrities.

In addition, Live-streaming shopping is a new form of social commerce, which shows its huge popularity under the influence of social media platforms [5]. As a special type of media, live streaming can record and broadcast in real-time. Therefore, a significant feature of live streaming is that customers can form a sense of telepresence. Also, live streaming shopping can induce fascination, which can lead to a sense of immersion [6].

As a result, this article is going to talk about how pop idols build up sets of characteristics to be idealized and appeal to the audiences which promote cognitive cultural economy and agglomeration economy. As a result, the theories of celebrity endorsement also applied in reality shows like Produce 101 when the sponsors chose popular trainees as the endorsers to their brands and inserted the commercials into the show.

\section{METHODS}

This paper is analyzing how trainees gain popularity and influence fandom culture through social media. To do so this paper is investigating data collected from social media platforms related to the reality show Produce 101 through an investigation of Tony $\mathrm{Yu}$, one of the candidates in "Youth With You" Season Three. Data have been collected from February 3 - April 9, 2021, and include his popularity index, as collected by Funji (an app collecting data on social media for celebrities in China) and crowdfunding data and the sales volume of the endorsed products as collected by Tony Yu's official fan club on Weibo (one of the mainstream social media platform in China, similar to Twitter and Instagram). The article also included some of Tony Yu's quotes in the show and other critics' comments toward him.

\section{FINDINGS}

\subsection{Popularity and characteristics}

Strong stage performing skills can help the trainees quickly catch the audiences' eyes out of hundreds of contestants.According to Weibo, 1.2 billion people viewed Youth With You Season 3, and over 433,000 fans discussed it when the first episode aired. Tony Yu's solo stage performance "Uranus" gained 1.9 billion views and
87000 discussions on Weibo, so he suddenly became more popular over other potential candidates after his first show in Youth With You. According to Funji, Tony Yu's fans on Weibo increased to 838000 in thirty days, which reached the peak compared to other trainees in the same program. He stayed in first place on "Jingdong Popular Trainee List" for all seven weeks from March 1st to April 18th. He also got 102.7 thousand of support and 1.45 billion of support as the top 1 on the lists of QQ music and Zhenguoli. Furthermore, he is the only one who has five one-take videos that have over 1 million views in Youth With You Season Three.

This data raised the queestion about how Tony $\mathrm{Yu}$ suddenly become so popular compared to other show participants. Going back to Produce 101 itself, the goal of the show is to form a group of nine trainees to debut, so the trainees who have excellent appearance and height with a comprehensive performing skill will be the appropriate candidates. As a result, the casting directors will pre-select some contestants they believe have the potential to debut and give them scripts and designs to highlight their unique characteristics while creating conflicts to attract the audiences (Lenz J,2018) [7]. One of the focuses of Produce 101 is to create suspense about who can finally debut as the center of the group through conflicts and competitions between the potential candidates. They are often experienced in the idol industry, for example, some of them were in closed training overseas for years and others were in another group before. However, their past could not help them gain enough opportunities to appear and perform on the screen, so they decided to participate in Produce 101 because they have solid foundations of stage performing with a large fan base [8]. Consequently, these potential trainees like Tony Yu can gain huge attention from their stage performances, which also helped them attract the audiences to vote. He ranked in the Top 20 participant on Produce X 101 in Korea and was frequently being discussed on social media as a hot candidate to debut as the center of the formed boy group. Although he did not successfully debut in Korea, his extraordinary performance attracted many k-pop fans and audiences that enjoy stage performances.

Other than the hardcore skills of performing, a prominent personality can also help the trainees to gain a lot of attention. A video of Tony Yu impersonating the Minions had over 243.8 million views with 27 thousand discussions according to Weibo. In the outtakes, Tony $\mathrm{Yu}$ revealed his charm through the talent of imitation and received a favorable review among the trainees because of his imitation of Donald Duck and Spongebob's voices. Besides, a reporter mentioned in his report of the press conference at the beginning of the show that Tony $\mathrm{Yu}$ bowed four or five times from the door to the stage which is the most compared to other trainees. Tony $\mathrm{Yu}$ said during the conference, another reporter asked him a trick question that, " Is Youth With You easier or less 
competitive than Produce X 101 in Korea?" Instead of giving an official answer to the public, Tony Yu brought his thoughts into the question, "I cannot control what is going on in the show, but I can control myself not to do the things that I should not." His modesty is one of the most important qualities an idol should possess, which gave a remarkable first impression to the media professionals and the audiences. In addition, Tony $\mathrm{Yu}$ also showed his desire and pursuit of the dream to be the center. A hidden rule in three seasons of Youth With You is that the center of the theme song will be the center of the debut group, however, Tony missed the chance to become the center of the theme song by a margin of two votes. In the first ranking release (40 trainees were cut from the show), Tony Yu got first place, he said in his speech that he wanted to break this record and become the final center of the group. Under the pressure of malicious editing, he still won a lot of audiences' hearts because of his ambition and sincerity to break the record with efforts. As a result, other than the hardcore skills of performing, a prominent personality can also help the trainees to gain a lot of attention [9]. The sincerity and loveliness of Tony Yu's character formed a sharp contrast with his mature stage performances, which showed his charm to the audiences in all aspects and gained a lot of attention on social media.

\subsection{Aggregated Economy and crowdfunding}

Under the great influence of social media, the trainees lead to a large scale of cultural and aggregated economy in fandom during Produce 101. According to Weibo, the total crowdfunding for Tony Yu was 12 million RMB by the end of April 8th which is 4 million higher than the second place. The total amount of crowdfunding by fans in less than two months is close to the top one percent of people who earn the highest wages per year in the world. The official fan clubs will normally be established after the show is publicly announced with the name list of the trainees. Online votes and beverage tickets are the two major voting channels for fans in Produce 101, so the official fan clubs often encourage the fans to vote together. Besides the online voting channel through the video platform of Produce 101, the beverage company often includes a virtual ticket or a 2D code on the drink to encourage the audiences of Produce 101 to buy more drinks. Therefore, compared to buying the drinks separately by fans, the official fan clubs adopt crowdfunding as a method to unify the purchase of beverages to prevent a huge waste of drinks and plagiarism in votes [10]. The official fan club will assign fans into different groups to increase efficiency because all of the paper tickets have to be scanned by hands, crowdfunding links are also used for compensation when someone accidentally votes for the wrong person in order to minimize the voting mistakes. Furthermore, crowdfunding is also necessary to buy the enormous video platform accounts distributed to fans because it is also valid to vote online.

To stimulate more fans participating in crowdfunding, the official fan clubs of the trainees often set three different types of crowdfunding links, including daily links, team-building links, and battle links. Daily links are set for a steady and consistent increase every day, team-building links are usually focused on a specific period for vigorous growth, and battle links are often set between two or more groups of trainees that strengthen the passion of wining through comparison. Other fan associations usually set a certain amount of money as a goal to encourage more fans to take part in the event. In addition, some entertainment companies employ professional fans disguising themselves as staff to spread fake or exaggerated news by cooperating with commercial accounts on social media. Consequently, various fan groups led to a massive scale of fundraising to increase the effectiveness and validity of votes.

\subsection{Celebrity endorsement}

Commercial resources provide more exposure for the trainees through commercials on the internet and entity advertising in public infrastructures and demonstrate their probative value that stabilizes their popularity and positions in Youth With You. In this case study example, Tony was invited to the live streaming held by L'oreal which is one of the sponsors of Youth With You Season three. Merchants would prepare a limited amount of the products with their signatures as gifts for the customers when the celebrities are invited to the live streaming to sell their products. Up to April 9th, the total sale of the sets of Age Perfect Nectar Royal Cream and Youth Code Serum is more than 247 thousand RMB. It is not surprising that Tony Yu's ability of product promotion was also largely outcompeting other trainees while he was being first place of the first and second ranking release in the show.

Celebrity endorsements are promoted according to the different sponsors and sponsors of Produce 101, it is purposeful to make use of the popularity of the show and the trainees themselves to advertise their products through the media platforms [1]. The sponsors majoring in cosmetic and clothing brands can effectively sell their products through celebrity endorsement. They concentrate on newly released Makeup, skin care products, and clothes with high utility and affordable price facing a highly diverse, female target audience who are also the target audience of Produce 101 [2]. The sponsors usually test the candidates by creating a voter ballot, and trainees who are on the top of the lists will be invited to shoot commercials or participate in individual live streams. Under the huge influence of social media platforms, live-streaming became a new welcoming way to shop online, especially among young women due to its feature of record and broadcast in real-time [5]. Live- 
streaming brings a sense of immersion while the merchant sets a limited amount of a specific product with a promotion price, which stimulates the customers who desire exclusivity [6]. As a result, the fans are motivated to buy the endorsed products to help the selected trainee to gain more opportunities in commercial resources.

Concentrated purchasing was also encouraged by Tony Yu's fans in magazines because magazines as the mainstream media can better expand the popularity of trainees through all age groups in both online and entity advertisements. He was the first contestant to be featured on two different magazine covers at the same time during Season 3 of Youth With You. According to Tony Yu's fan club official data collection, the total sales volume of Nandu Magazine and Starbox Magazine were over 385 thousand RMB, which maintained the highest level of purchasing power among other fans under the condition of frequent and large scale crowdfunding for paper tickets at the same time. The magazine covers and interviews helped more people learn about Tony Yu's experiences, helping him gain more attention [11]. In addition, the trainees can enrich their fashion style by changing their outlooks to show more possibilities to more people in entity advertisement. As a result, the fans centralized to buy magazines to expand fashion resources and maintain a good relationship with the brands for their idols.

Despite a few hypotheses discussing that celebrity endorsement provides credibility and enhances perceptions of quality to the customers, they can also relate a specific function or trait illustrated by the celebrity to the products [3]. As a result, the derivative products of the trainees are also promoted by the sponsors of Youth With You. The total sales volume of the derivative products can directly reflect the popularity and favorability of a specific trainee particularly. Besides, It is memorable to the audiences if they could get the postcards or Polaroids with their idols' signatures. The derivative products are special to the fans because they are the emotional sustenance that held great sentimental values to the fans. Because of the unreachable distances between celebrities and fans, the derivative products are the media that connect the fans with their idols, they play an important role as a substitute for the celebrities. Robinette noted the emotional connection between the derivative products with the customer that, "From almost the dawn of time, companies and advertising agencies have known that tapping into an audience's emotions love, fear, pride, jealousy, pleasure — is a highly effective way to get consumers to pay attention to their products and services". Therefore, the emotional bonds between the derivative products and celebrities are influential to the customers' purchase decisions.

\section{CONCLUSION}

According to all the information mentioned above, some limitation of the article still exists because it only analyzed a single trainee in one season of Youth With You. Nevertheless, it still reveals that behind the popularity of this kind of reality show is a complete industrial channel with trainees as commodities. The contestants attract fans through marketing and advertising on social media and video platforms, as well as their stage performing abilities and personalities that lead to massive fundraising and fandom economy. The trainees also maintained their popularity and gained more attention through the endorsements of sponsored products. However, it is thought-provoking that Produce 101 supposed to be the stage that offers opportunities to enormous trainees to realize their dreams to sing and dance, but the video platforms, social media, and sponsors focused on consuming and taking advantages from fans and audiences to obtain huge profits, which lost the original intention of Produce 101 that offers talented teenagers a platform of stage performance.

\section{REFERENCES}

[1]. Aw, Eugene Cheng-Xi, and Lauren I. Labrecque. 《Celebrity endorsement in social media contexts: understanding the role of parasocial interactions and the need to belong 》. Journal of Consumer Marketing 37, 895-908. https://doi.org/10.1108/JCM-10-2019-3474.

[2]. Baxter P, Jack S. Qualitative case study methodology: Study design and implementation for novice researchers[J]. The qualitative report, 2008, 13(4): 544-559.

[3]. Clark, Robert C. and Horstman, Ignatius J. (2003) Celebrity Endorsements (www.bu.edu/ e.con/seminar/micro/pdffav) celebendorse.bu.pdf "Is celebrity advertising effective Business Standards" Dec 05, 2003

[4]. Danescu-Niculescu-Mizil C, Kossinets G, Kleinberg $\mathrm{J}$, et al. How opinions are received by online communities: a case study on amazon. com helpfulness votes[C]//Proceedings of the 18th international conference on World wide web. 2009: 141-150.

[5]. Ellis. 《Celebrity Culture》. The Blackwell Encyclopedia of Sociology. American Cancer Society, 2007. https://doi.org/10.1002/9781405165518.wbeosc01 $\underline{4}$ 
[6]. Gerring, John. 《What Is a Case Study and What Is It Good for?》 The American Political Science Review 2 (2004): 341-54.

Held G. Magazine covers-a multimodal pretextgenre[J]. 2005.

[7]. Khatri, Dr. Puja. *Faculty member, Apeejay School of Management, Dwarka, New Delhi Celebrity Endorsement: A Strategic Promotion Perspective.

[8]. Marwick A, Boyd D. To see and be seen: Celebrity practice on Twitter[J]. Convergence, 2011, 17(2): 139-158.

[9]. Niemann-Lenz J, Gölz H, Schenk M. Why do adolescents watch scripted reality tv? A typology based on viewing motives[J]. Youth and Media: Current Perspectives on Media Use and Effects, 2018, 38: 19 .

[10]. Prakash S, Singh A, Yadav K S. Personality (Introvert, And Extrovert) and Professional Commitment Effect among B. Ed Teacher Educator Students $[\mathrm{J}]$. The International Journal of Indian Psychology, 2016, 3(2): 43-49.

[11]. Robinette S, Lenz V. Emotion marketing[J]. Telephony, 2003, 19: 40-41.

[12]. Shin, D.-H., 2017. The role of affordance in the experience of virtual reality learning: technological and affective affordances in virtual reality. Telemat.
Inform.
34
(8),
1826-1836. https://doi.org/10.1016/j.tele.2017.05.013.

[13]. Sun, Yuan, Xiang Shao, Xiaotong Li, Yue Guo, Kun Nie. 《How Live Streaming Influences Purchase Intentions in Social Commerce: An IT Affordance Perspective 》. Electronic Commerce Research and Applications 37: 100886. https://doi.org/10.1016/j.elerap.2019.100886

[14]. Zainal, Zaidah. 《Case Study As a Research Method 》. Jurnal Kemanusiaan 5, 1 (2007). https://jurnalkemanusiaan.utm.my/index.php/kema nusiaan/article/view/165. 